\title{
Desafios à Educação em Ciências em Tempos Conturbados
}

\section{Pedro Reis}

Universidade de Lisboa, Instituto de Educação, Lisboa, Portugal. E-mail: preis@ie.ulisboa.pt

Vivemos momentos de retrocesso no que respeita à democracia, aos direitos humanos, à justiça social e ao bem-estar de indivíduos, sociedades e ambientes. Várias comunidades sofrem politicamente, emocionalmente e fisicamente, por causa de uma sociedade que não cuida da totalidade dos seus membros, ignorando os mais vulneráveis e sujeitando-os a condições de vida deploráveis e a comportamentos discriminatórios e persecutórios influenciados pela ignorância, pelo preconceito e pela intolerância.

Os efeitos negativos do neoliberalismo e da globalização têm-se intensificado e as instituições sociais e políticas parecem incapazes ou não estão dispostas a responder efetivamente às múltiplas situações de injustiça. As assimetrias sociais têm se agravado, perpetuando um sistema que beneficia apenas uma pequena minoria, à custa da degradação do ambiente, da exploração incontrolada e insustentável dos recursos e do sofrimento e da exclusão da maior parte da população.

Muitos cidadãos não se sentem capacitados e empoderados para compreenderem e tomarem decisões sobre os problemas sociais e ambientais que afetam as suas comunidades e, ao mesmo tempo, a confiança nos representantes políticos tem diminuído e a apatia política têm ganho terreno, abrindo espaço a movimentos populistas e a uma eventual 'recessão democrática'.

O desconhecimento de uma parte significativa da população acerca do que é a ciência, associado à desinformação disseminada por determinados grupos, cria um ambiente propício ao aparecimento e proliferação de visões distorcidas e erróneas e de movimentos anti ciência.

O clima político e social global está saturado de raiva, medo, desinformação, desconfiança e desânimo. A polarização política alastra pelo planeta e repercute-se em divisões e conflitos entre países e dentro das comunidades e das famílias.

Como podemos contrariar esta situação na perspectiva da educação em ciências? Que desafios se colocam à educação em ciências no combate às causas de tais problemas e injustiças? 


\section{Desafio 1 - Uma Educação em Ciências para a Transformação Social}

Os problemas sociais e ambientais que as diferentes comunidades enfrentam e a dificuldade da população em envolver-se ativamente no desenvolvimento de soluções para esses problemas tornam urgente uma deslocação do foco da educação em ciências da transmissão de conhecimentos para a promoção de competências que assegure não apenas a formação de cientistas e especialistas, mas, também, uma educação científica alargada a todos os cidadãos. Uma educação em ciências que não se centre na promoção da adaptação e da conformidade dos cidadãos às regras e às condições atuais da nossa sociedade e das nossas comunidades, mas que se preocupe com a capacitação e o empoderamento dos cidadãos para uma transformação democrática, colaborativa e fundamentada em ciência da sociedade (SCHUTZ, 2019). Uma transformação participada na qual professores e alunos se assumam como agentes de mudança comprometidos com uma visão para a sociedade, quebrando um conjunto de práticas burocráticas/sufocadoras que parecem destinar-se a mantê-los cansados, anestesiados e sem capacidade de (re) ação.

Segundo esta perspectiva, a educação em ciências assume-se como uma força democratizadora e um catalisador para o desenvolvimento individual e a transformação social. Desta forma, a escola assume-se como um foro vivo para o diálogo libertador e não como uma instituição destinada ao ensino para o exame, a conformidade social e a competição entre os indivíduos e as sociedades (KELLNER; KIM, 2010).

\section{Desafio 2 - Uma Concepção de Ciência como Atitude Crítica, Questionadora e de Autonomia Intelectual}

Atualmente, uma parte considerável dos cidadãos ainda partilha uma concepção ultrapassada de ciência, como corpo de conhecimentos definitivos e inquestionáveis, construído por cientistas através de um processo neutro e objetivo. Esta imagem da ciência: (a) deturpa seriamente a natureza da ciência e a prática científica; (b) dissuade os cidadãos do escrutínio crítico ao apresentar o conhecimento científico como uma coleção de afirmações fixas e não questionáveis efetuadas por especialistas; (c) contribui para a interiorização de uma dependência intelectual dos cidadãos relativamente a especialistas; e, (d) promove uma sensação de falta de poder entre os cidadãos (BENCZE; CARTER, 2011; BENCZE; SPERLING, 2012)

O caráter conturbado da sociedade atual justifica uma educação científica que estimule, na população, uma concepção de ciência: (a) como processo de construção de conhecimento, condicionado por contextos sociais, históricos e culturais e em interação constante com a tecnologia, a sociedade e o ambiente; e, (b) como atitude crítica, questionadora e de autonomia intelectual perante as notícias divulgadas pelos media, as propostas de determinados grupos e os acontecimentos da vida quotidiana, idealmente alargada a todos os cidadãos e que não se assuma como privilégio de um pequeno grupo de especialistas (MATTHEWS, 2015; MCCAIN; KAMPOOURAKIS, 2020). Uma concepção de ciência que facilitará a colaboração e a mobilização de todos os cidadãos no sentido de: (a) exigirem e exercerem uma cidadania participativa e fundamentada sobre questões 
relacionadas com ciência e tecnologia; e, (b) exigirem justiça social e ética nas interações entre ciência, tecnologia, sociedade e ambiente.

\section{Desafio 3 - A Capacitação e o Empoderamento dos Cidadãos para a Ação Fundamentada}

Muito existe para fazer no sentido da capacitação e do empoderamento dos cidadãos para uma participação ativa e fundamentada (em conhecimento científico) em processos de tomada de decisão e de ação (individual e coletiva) sobre as problemáticas que afetam as nossas sociedades/comunidades, com consequentes implicações na qualidade de vida e na justiça social. Neste processo, a educação em ciência desempenha sempre um papel (positiva ou negativamente) relevante, consoante as ações dos educadores. Práticas tradicionais, marcadas pela falta de dialogismo e por uma educação bancária (FREIRE, 1974) que não tem em conta as necessidades e os interesses dos alunos, aumentam a invisibilidade social dos cidadãos e reforçam a sua dependência relativamente às opiniões, às decisões e aos interesses de grupos restritos (políticos, cientistas, especialistas, etc.) que nem sempre parecem atuar em prole do bem-comum. Práticas educativas que reconhecem aos alunos (independentemente da sua idade) o direito de participação/envolvimento na identificação dos problemas que afetam as suas comunidades e na construção, discussão e tomada de decisões sobre possíveis soluções para esses problemas, aumentam a autonomia intelectual dos cidadãos e permitem-Ihes assumirem-se como protagonistas sociais, capazes de assumirem a responsabilidade pelo futuro das suas vidas e das suas comunidades (ALSOP; BENCZE, 2014). Estas práticas, promotoras de uma atitude crítica e investigativa, investem os cidadãos com as competências necessárias ao pensamento, à discussão, à tomada de decisão e à ação, tornando-os construtores de conhecimentos socialmente relevantes, em vez de simples consumidores acríticos de conhecimento (como outras práticas parecem estimular) (BENCZE; SPERLING, 2012). Através deste tipo de práticas emancipadoras, qualquer aluno, independentemente da sua idade, é reconhecido como cidadão pela ação extremamente influente que pode desempenhar junto das suas famílias e grupos de amigos.

Para tal, torna-se necessário: (a) garantir que crianças e jovens tenham oportunidades de participar de maneira significativa na sua vida diária, através da disponibilização de espaços informais e formais (em diferentes níveis, nomeadamente, casa, escola, comunidade, organizações e associações) em que possam articular suas próprias expressões de cidadania ativa por meio de diferentes formas de participação; (b) estimular as crianças e jovens a assumirem níveis elevados de responsabilidade e de ação no exercício de uma cidadania ativa; e, (c) incentivar os adultos a assumirem um papel de facilitadores e defensores - e não de controladores - na realização de ações (envolvendo crianças, jovens e adultos) centradas em preocupações comuns e que facilitem o desenvolvimento de uma cultura de respeito e de confiança mútua (HART, 2008; PETERSON, 2018; SCHULZ et al., 2018). 


\section{Desafio 4 - Uma Concepção de Currículo Fortemente Contextualizado e Centrado em Competências Adequadas à Promoção do Bem-estar das Populações e dos Ecossistemas e à Justiça Social}

Algumas concepções limitadas/restritas de currículo - como listado de conteúdos a abordar exaustivamente e de forma descontextualizada das vidas dos alunos - relegam os professores/educadores para um papel de funcionário que se limita a executar de forma acrítica as orientações de política educativa impostas por determinados grupos. Neste tipo de contexto, os professores/educadores sentem-se, frequentemente, sobrecarregados / cansados / anestesiados por tarefas burocráticas e afastados da reflexão e da decisão. Contudo, a concretização de uma educação em ciência socialmente relevante e empoderadora dos cidadãos requer uma concepção de currículo diferente, como o conjunto de aprendizagens (conhecimentos, capacidades e atitudes) consideradas importantes num determinado contexto histórico e social, marcado por determinadas exigências específicas. Segundo esta concepção de currículo, cabe às sociedades/ comunidades identificarem o conjunto de conhecimentos considerados mais adequados à superação bem-sucedida dos desafios com os quais as comunidades são confrontadas. Neste contexto, o professor assume-se como um construtor de currículo (HARGREAVES, 2000): um especialista e um decisor capaz de contribuir para o desenvolvimento de um currículo centrado em competências promotoras do bem-estar das populações e dos ecossistemas e da justiça social (HADJICHAMBIS et al., 2020; REIS, 2020).

Na opinião de Hodson (1998, p. 4, tradução nossa), qualquer currículo de ciências deverá preparar para a ação sociopolítica, através de uma educação científica centrada em problemáticas e muito mais politizada que equipe os alunos com "[...] a capacidade e o comprometimento de realizar ações apropriadas, responsáveis e eficazes sobre questões de teor social, económico, ambiental e moral-ético". Este tipo de currículo deverá: (a) basear-se em assuntos locais, regionais, nacionais e globais, considerados socialmente relevantes pelo professor e pelos alunos; (b) apresentar a ciência e a tecnologia como empreendimentos humanos; (c) propor uma educação científica e tecnológica politizada e imbuída de valores humanos e ambientais; e, (d) onde alunos, professores e membros das comunidades tenham a oportunidade de realizar investigações científicas e de se envolver na implementação de soluções (fundamentadas em dados científicos) para problemas que considerem relevantes. Os currículos de ciências fortemente contextualizados - centrados em situações e problemas reais das comunidades em que vivem os alunos - reforçam a percepção dos alunos relativamente à relevância social da educação em ciência e à importância da ciência para a resolução dos problemas que afetam as comunidades.

\section{Desafio 5 - A Avaliação ao Serviço do Desenvolvimento Individual e da Transformação Social}

Numa perspectiva de educação em ciências como processo centrado na promoção de competências necessárias à resolução dos problemas sociais e ambientais atuais, a avaliação assume uma importância fulcral. A avaliação destas competências apenas se torna possível desde que realizada de forma contextualizada, em situações reais nas quais as competências possam ser observadas em ação (enquanto os alunos identificam 
problemas, averiguam as suas causas, desenvolvem possíveis soluções e colocam em prática essas soluções) (BLACK; HARRISON, 2010). Apenas no contexto destas ações reais se torna possível concluir se os alunos se tornaram ou não competentes. Desta forma a avaliação passa a estar ao serviço do desenvolvimento individual e da transformação social em vez de estar ao serviço do exame, da conformidade social e da competição entre os indivíduos e as sociedades.

\section{Desafio 6 - Uma Formação Contínua com maior Impacto na Competência Profissional dos Professores e nos Resultados de Aprendizagem dos seus Alunos}

A resposta aos grandes desafios com que a escola atual é confrontada requer uma formação contínua de professores fortemente contextualizada, ou seja, centrada nas necessidades específicas de determinados docentes e escolas e que utilize a escola e a sala de aula como o lugar privilegiado para um desenvolvimento profissional relevante e um maior impacto nos alunos. A maior contextualização e o consequentemente reforço da relevância da formação de professores permitirão acompanhar o desenvolvimento de competências profissionais - o saber dos professores - com as condições de motivação o querer - e os meios de realização - o poder - indispensáveis para que as competências se traduzam em práticas educativas eficazes (CAMPOS, 2011).

O desenvolvimento de comunidades de prática - envolvendo a colaboração de diferentes agentes educativos na análise de problemas e na implementação e avaliação de propostas de solução - tem-se revelado uma modalidade eficaz na melhoria do ensino em contextos específicos, proporcionando uma estrutura de apoio a iniciativas de inovação que combate sentimentos de isolamento e de desânimo e promove, simultaneamente, o desenvolvimento individual e coletivo e a transformação social (DAVIS, 2003; REIS, 2014, 2016; REIS; GALVÃO; BAPTISTA, 2018). Nas comunidades de prática em contexto escolar, os docentes associam-se e interagem motivados por interesses comuns e pelo desejo de melhorar a sua prática educativa através: (a) da partilha de conhecimentos, experiências, ideias e competências; e (b) do envolvimento em dinâmicas de pesquisa-reflexão-ação centradas na resolução de problemas específicos por eles diagnosticados, através da introdução de abordagens educativas inovadoras (WENGER, 1998, 2010).

\section{Desafio 7 - A Supervisão de Professores como Processo Emancipatório}

A supervisão pedagógica em contexto escolar assume-se cada vez mais como uma estratégia adequada à capacitação dos professores para o exercício da sua profissão nos tempos atuais. Trata-se de um processo que pretende reforçar a capacidade das escolas contribuírem para a educação e o sucesso académico de cada um dos seus alunos, através da promoção da interação, da capacidade de resolução de problemas e do desenvolvimento profissional dos professores (FULLAN; HILL; CRÉVOLA, 2006; REIS, 2011; SERGIOVANNI; STARRATT, 2007). Pode acontecer em diferentes situações, nomeadamente, no âmbito de: (1) um estágio de iniciação à prática profissional que proporcione o contato com práticas de ensino particularmente interessantes e o desenvolvimento das competências profissionais dos estagiários; (2) um período de indução profissional 
centrado na integração de docentes numa comunidade educativa e em determinadas funções a desempenhar; ou, (3) uma iniciativa de desenvolvimento profissional na escola que apoie a identificação e a superação de fragilidades individuais e coletivas. No entanto, independentemente da situação em que ocorra, o desafio que se coloca à supervisão é a da transição de uma perspectiva de pendor mais controlador e inspectivo - centrada na avaliação dos professores e desencadeando sentimentos de negativos que comprometem o caráter desenvolvimentista deste processo - para uma perspectiva de emancipação e autonomia que capacite os sujeitos envolvidos para a transformação das práticas escolares e sociais.

A perspectiva mais inspectiva da supervisão surge como uma forma de "afinar" o ensino e de controlar e forçar os professores em determinadas direções consideradas desejáveis pelas lideranças de topo da escola. São realizadas de forma hierárquica - no sentido do especialista para o subordinado - constituindo um processo individualista e hierárquico de aprender sobre o ensino que estimula uma postura passiva, dependente e adaptativa entre os professores. Fortemente centradas na manutenção de regras e padrões de ação, estes tipos de supervisão reduzem o papel dos professores ao de funcionários que se limitam à implementação de currículos, práticas e avaliações impostos por outros. Consequentemente, não preparam para a mudança/transformação, acabando por perpetuar o status quo ao constituírem uma atividade conservadora que mantem as práticas e as estruturas existentes (SMYTH, 1988).

A perspectiva emancipatória da supervisão apresenta uma natureza colaborativa, diferenciada e desenvolvimentista, adequada às necessidades de desenvolvimento de cada professor (ALARCÃO; ROLDÃO, 2008; GLICKMAN; GORDON; ROSS-GORDON, 2007). Desta forma, assume-se como um processo emancipatório em que os professores se auxiliam no sentido de ganharem controlo sobre as suas vidas profissionais e de transcenderem e transformarem o seu ensino e o contexto social e cultural em que trabalham, tendo em vista uma sociedade mais justa e mais sustentável ambientalmente (SMYTH, 1986). Neste processo supervisivo, entre pares, os professores assumem-se como agentes ativos (a) na mudança das suas práticas, (b) na adaptação dos currículos ao que consideram serem as necessidades dos seus alunos e das comunidades em que vivem, e, (c) na transformação da sociedade e das suas vidas pessoais.

\section{Desafio 8 - A Utilização da Web 2.0 no Apoio à Ação sobre Problemas Sociais e Ambientais}

As ferramentas da Web 2.0 podem ser bastante poderosas na implementação de ações coletivas sobre problemáticas sociais e ambientais (REIS, 2013). Muitos movimentos sociais (de jovens e adultos) têm utilizado as ferramentas da Web 2.0 para romperem agendas mediáticas dominantes e mobilizarem cidadãos para novas formas de organização e ação sociopolítica (CANDÓN-MENA; BENÍTEZ-EYZAGUIRRE, 2016). Diversas redes sociais têm dado protagonismo social a grupos de cidadãos tradicionalmente afastados dos monopólios mediáticos - dominados por estados ou grupos económicos - permitindo a criação e o acesso a espaços virtuais mais democráticos que a facilitam a rápida interação e o intercâmbio de ideias entre um número extremamente elevado de indivíduos. Contudo, também têm sido estas redes sociais a facilitar a disseminação de propaganda 
e de informação errada ou distorcida entre a população mundial, manipulando a opinião pública e o comportamento dos cidadãos, promovendo ideias erradas sobre a ciência e convidando ao ódio e ao fanatismo (ASHLEY, 2020; LANIER, 2018; VAIDHYANATHAN, 2018). A desordem da informação, desencadeada pelo acesso facilitado à Internet de grupos interessados na manipulação da opinião pública, afeta particularmente as comunidades com baixos níveis de alfabetização mediática e de alfabetização científica (LOPES, 2019; WARDLE, 2019; WARDLE; DERAKHSHAN, 2017). Logo, a promoção destes tipos de alfabetização assume um caráter prioritário no combate a todos os problemas resultantes da desordem da informação (IRETON; POSENTTI, 2018; WARDLE, 2019).

Contudo, apesar destes aspetos negativos, as ferramentas da Web 2.0 podem ter um forte impacto no empoderamento cultural, social e político dos cidadãos (KELLNER; KIM, 2010; ZORAS; BENCZE, 2014), sendo mais eficazes na promoção da participação cívica do que os media tradicionais (KAHNE; NAM-JIN LEE; FEEZELL, 2013; SEGERBERG; BENNETT, 2011) e permitindo a todos os cidadãos expressar as suas visões e assumir protagonismo na divulgação de determinadas propostas de resolução de problemas sociais e ambientais (GARCÍA BERMÚDEZ; REIS, VÁZQUEZ-BERNAL, 2014, 2017; KRSTOVIC, 2014; MARQUES; REIS, 2017a, 2017b; SCHEID; REIS, 2016; ZORAS; BENCZE, 2014).

\section{Considerações Finais}

Os desafios à educação em ciências que aqui se apresentam não são novos. Contudo, o contexto social e ambiental atual demonstra a sua atualidade extrema. A concretização destes desafios promoverá: (a) o reconhecimento da dignidade e do valor inerentes a todos os seres humanos; (b) o pensamento crítico e a autonomia intelectual dos cidadãos, num clima de liberdade de pensamento e de manifestação; (c) o empoderamento alargado dos cidadãos para uma participação fundamentada e ativa na evolução da sua vida e na resolução dos problemas que a afetam; (d) o reforço do direito de toda a pessoa tomar parte livremente na vida da comunidade e de contribuir de forma ativa e informada para uma sociedade e um ambiente saudáveis.

\section{Referências}

ALARCÃO, I.; ROLDÃO, M. C. Supervisão: um contexto de desenvolvimento profissional dos professores. Mangualde: Pedagogo, 2008.

ALSOP, S.; BENCZE, L. Activism!: toward a more radical science and technology education. In: BENCZE, L.; ALSOP, S. (ed.). Activist science and technology education. Dordrecht: Springer, 2014. p. $1-19$.

ASHLEY, S. News literacy and democracy. New York: Routledge, 2020.

BENCZE, L.; CARTER, L. Globalizing students acting for the common good. Journal of Research in Science Teaching, Hoboken, v. 48, n. 6, p. 648-669, 2011. DOI: https://doi.org/10.1002/tea.20419.

BENCZE, J. L.; SPERLING, E. R. Student-teachers as advocates for student-led research-informed socioscientific activism. Canadian Journal of Science, Mathematics \& Technology Education, Heidelberg, v. 12, n. 1, p. 62-85, 2012. DOI: https://doi.org/10.1080/14926156.2012.649054. 
BLACK, P.; HARRISON, C. Formative assessment in science. In: OSBORNE, J.; DILLON, J. (ed.). Good practice in science teaching: what research has to say. 2 nd. ed. Maidenhead: Open University Press, 2010. p. xx.

CAMPOS, B. P. Formação de professores em serviço para a mudança no desempenho profissional. In: SERRASINA, M. L.; GOMES, F.; ROSA, J.; PORTELA, J. (org.). Formação contínua: relatos e reflexões. Lisboa: Escola Superior de Educação: Instituto Politécnico de Lisboa, 2011. p. 217-228. Disponível em: https://repositorio.ipl.pt/handle/10400.21/3370. Acesso em: 18 fev. 2021.

CANDÓN-MENA, J.; BENÍTEZ-EYZAGUIRRE, L. (ed.). Activismo digital y nuevos modos de ciudadanía: una mirada global. Bellaterra: Institut de la Comunicació, 2016. Disponível em: https://hdl.handle. net/11441/86686. Acesso em: 18 fev. 2021.

DAVIS, K. "Change is hard": what science teachers are telling us about reform and teacher learning of innovative practices. Science Education, Hoboken, v. 87, n. 1, p. 3-30, 2003.

FREIRE, P. Pedagogia do oprimido. Rio de Janeiro: Paz e Terra, 1974.

FULLAN, M.; HILL, P.; CRÉVOLA, C. (ed.). Breakthrough. Thousand Oaks, CA: Corwin, 2006.

GARCÍA-BERMÚDEZ, S.; REIS, P.; VÁZQUEZ-BERNAL, B. Potencialidades y limitaciones de los entornos virtuales colaborativos y las herramientas web 2.0 en la promoción del activismo sobre cuestiones ambientales en estudiantes de básica secundaria. Uni/Pluriversidad, Antioquia, v. 41/14, n. 2, p. 502-507, 2014.

GARCÍA-BERMÚDEZ, S.; REIS, P.; VÁZQUEZ-BERNAL, B. Promoción del activismo sobre cuestiones ambientales en estudiantes de básica secundaria a través de las herramientas web 2.0. Da Investigação às Práticas, Lisboa, v. 7, n. 2, p. 34-53, 2017. Disponível em: http://www.scielo.mec.pt/ scielo.php?script=sci_arttext\&pid=S2182-13722017000200004. Acesso em: 18 fev. 2021.

GLATTHORN, A. A. Differentiated supervision. Alexandria: Association for Supervision and Curriculum Development, 1997.

GLICKMAN, C. D.; GORDON, S.; ROSS-GORDON, J. SuperVision and instructional leadership: a developmental approach. 7. ed. Boston: Pearson Education, 2007.

HADJICHAMBIS, A. C. et al. (ed.). Conceptualizing environmental citizenship for 21st century education. Cham: Springer, 2020.

HARGREAVES, A. Four ages of professionalism and professional learning. Teachers and Teaching: history and practice, Abingdon, v. 6, n. 2, p. 151-182, 2000. DOI: https://doi. org/10.1080/713698714.

HART, R. Stepping back from 'the ladder': reflections on a model of participatory work with children. In: REID, A. B. (ed.). Participation and learning: perspectives on education and the environment, health and sustainability. Dordrecht: Springer, 2008. p. 19-31.

HODSON, D. Teaching and learning science: towards a personalized approach. Buckingham: Open University Press, 1998.

IRETON, C.; POSENTTI, J. Introduction in journalism, fake news e disinformation: handbook for journalism education and training. Paris: UNESCO, 2018.

KAHNE, J.; NAM-JIN LEE; FEEZELL, J. T. The civic and political significance of online participatory cultures among youth transitioning to adulthood. Journal of Information Technology and Politics, London, v. 10, n. 1, p. 1-20, 2013. DOI: https://doi.org/10.1080/19331681.2012.701109.

KELLNER, D.; KIM, G. YouTube, critical pedagogy, and media activism. The Review of Education, Pedagogy, and Cultural Studies, New York, v. 32, n. 1, p. 3-36, 2010. 
KRSTOVIC, M. Preparing students for self-directed research-informed actions on socioscientific issues. In: BENCZE, L.; ALSOP, S. (ed.). Activist science and technology education. Dordrecht: Springer, 2014. p. 399-417.

LANIER, J. Ten arguments for deleting your social media accounts right now. London: Henry Holt, 2018.

LOPES, P. Mentiras, pegadas e algoritmos: da necessidade de uma educação para os media. In: LOPES, P.; REIS, B. (ed.). Comunicação digital: media, práticas e consumos. Lisboa: Núcleo de Investigação em Práticas \& Competências Mediáticas, 2019. p. 137-156. Disponível em: https:// nipcom.autonoma.pt/comunicacao-digital-media-praticas-e-consumos/. Acesso em: 12 fev. 2021.

MARQUES, A. R.; REIS, P. Producción y difusión de vídeos digitales sobre contaminación ambiental. Estudio de caso: activismo colectivo basado en la investigación. Revista Eureka sobre Enseñanza y Divulgación de las Ciencias, Cadiz, v. 14, n. 1, p. 215-226, 2017a. Disponível em: https://revistas.uca. es/index.php/eureka/article/view/3011. Acesso em: 12 fev. 2021.

MARQUES, A. R.; REIS, P. Research-based collective activism through the production and dissemination of vodcasts about environmental pollution in the $8^{\text {th }}$ grade. Sisyphus: journal of education, Poland, v. 5, n. 2, p. 116-137, 2017b.

MATTHEWS, M. Science teaching: the contribution of history and philosophy of science: $20^{\text {th }}$ anniversary revised and expanded edition. New York: Routledge, 2015.

MCCAIN, K.; KAMPOOURAKIS, K. (ed.). What is scientific knowledge?: an introduction to contemporary epistemology of science. New York: Routledge, 2020.

PETERSON, T. H. Student development and social justice: critical learning, radical healing, and community engagement. London: Palgrave Macmillan, 2018.

REIS, P. Da discussão à ação sócio-política sobre controvérsias sócio-científicas: uma questão de cidadania. Ensino de Ciências e Tecnologia em Revista, Santo Ângelo, v. 3, n. 1, p. 1-10, 2013.

REIS, P. Environmental citizenship \& youth activism. In: HADJICHAMBIS, A. C. et al. (ed.). Conceptualizing environmental citizenship for $21^{\text {st }}$ century education. Cham: Springer, 2020. p. 139148.

REIS, P. Observação de aulas e avaliação do desempenho docente. Lisboa: Ministério da Educação: Conselho Científico para a Avaliação de Professores, 2011.una mirada global. Bellaterra: Institut de la Comunicació, 2016. Disponível em: https://hdl.handle.net/11441/86686. Acesso em: 18 fev. 2021.

REIS, P. O papel das comunidades de prática na formação do desenvolvimento profissional de professores e do diálogo entre a escola e a universidade. In: GENOVESE, L. G. R.; MORAES, A. G.; BOZELLI, F. C.; GEHLEN, S. T.; MIQUELIN, A. F.; SASSERON, L. H. (org.). Diálogo entre as múltiplas perspectivas na pesquisa em ensino de física. São Paulo: Livraria da Física, 2016. p. 173-194.

REIS, P. Promoting students' collective socio-scientific activism: teacher's perspectives. In: BENCZE, L.; ALSOP, S. (ed.). Activist science and technology education. Dordrecht: Springer, 2014. p. 547-574.

REIS, P.; GALVÃO, C.; BAPTISTA, M. Formação contínua de professores e comunidades de prática: perspectivas da Universidade de Lisboa. In: CACHAPUZ, A. F.; SHIGUNOV NETO, A.; FORTUNATO, I. (org.). Formação inicial e continuada de professores de ciências: o que se pesquisa no Brasil, Portugal e Espanha. São Paulo: Hipótese, 2018. p. 257-275.

SCHEID, N.; REIS, P. As tecnologias da informação e da comunicação e a promoção da discussão e ação sociopolítica em aulas de ciências naturais em contexto português. Ciência \& Educação, Bauru, v. 22, n. 1, p. 129-144, 2016. DOI: https://doi.org/10.1590/1516-731320160010009.

SCHULZ, W. et al. Becoming citizens in a changing world: IEA international civic and citizenship education study 2016 international report. Amsterdam: IEA: Springer, 2018. 
SCHUTZ, A. Empowerment: a primer. New York: Routledge, 2019.

SEGERBERG, A.; BENNETT, W. L. Social media and the organization of collective action: using twitter to explore the ecologies of two climate change protests. The Communication Review, Philadelphia, v. 14, n. 3, p. 197-215, 2011.

SERGIOVANNI, T. J.; STARRATT, R. J. Supervision: a redefinition. New York: McGraw Hill, 2007.

SMYTH, J. Clinical supervision: technocratic mindedness, or emancipatory learning. Journal of Curriculum and Supervision, Alexandria, VA, v. 1, n. 4, p. 331-340, 1986.

SMYTH, J. A "critical" perspective for clinical supervision. Journal of Curriculum and Supervision, Alexandria, VA, v. 3, n. 2, p. 136-156, 1988.

VAIDHYANATHAN, S. Antisocial media: how facebook disconnects us and undermines democracy. New York: Oxford University Press, 2018.

WARDLE, C. Understanding information disorder. London: First Draft, 2019.

WARDLE, C.; DERAKHSHAN, H. Information disorder: toward an inter-disciplinary framework for research and policymaking. Strasbourg: Council of Europe, 2017. Disponível em: https://rm.coe.int/ information-disorder-toward-an-interdisciplinary-framework-for-researc/168076277c. Acesso em: 18 fev. 2021.

WENGER, E. Communities of practice: learning, meaning, and identity. Cambridge: Cambridge University Press, 1998.

WENGER, E. Communities of practice and social learning systems: the career of a concept. In: BLACKMORE C. (ed.). Social learning systems and communities of practice. London: Springer, 2010. p. 179-198.

ZORAS, B.; BENCZE, L. Utilizing social media to increase student-led activism on STSE issues. In: BENCZE, L.; ALSOP, S. (ed.). Activist science and technology education. Dordrecht: Springer, 2014. p. 435-449. 